\title{
Physics Features of TRU-Fueled VHTRs
}

\author{
Tom G. Lewis III and Pavel V. Tsvetkov \\ Department of Nuclear Engineering, Texas A\&M University, 129 Zachry Engineering Center, 3133 TAMU, College Station, \\ TX 77843-3133, USA
}

Correspondence should be addressed to Pavel V. Tsvetkov, tsvetkov@tamu.edu

Received 9 April 2009; Accepted 14 April 2009

Recommended by Jan Leen Kloosterman

The current waste management strategy for spent nuclear fuel (SNF) mandated by the US Congress is the disposal of high-level waste (HLW) in a geological repository at Yucca Mountain. Ongoing efforts on closed-fuel cycle options and difficulties in opening and safeguarding such a repository have led to investigations of alternative waste management strategies. One potential strategy for the US fuel cycle would be to make use of fuel loadings containing high concentrations of transuranic (TRU) nuclides in the next-generation reactors. The use of such fuels would not only increase fuel supply but could also potentially facilitate prolonged operation modes (via fertile additives) on a single fuel loading. The idea is to approach autonomous operation on a single fuel loading that would allow marketing power units as nuclear batteries for worldwide deployment. Studies have already shown that high-temperature gas-cooled reactors (HTGRs) and their Generation IV (GEN IV) extensions, very-high-temperature reactors (VHTRs), have encouraging performance characteristics. This paper is focused on possible physics features of TRU-fueled VHTRs. One of the objectives of a 3-year U.S. DOE NERI project was to show that TRU-fueled VHTRs have the possibility of prolonged operation on a single fuel loading. A 3D temperature distribution was developed based on conceivable operation conditions of the 600 MWth VHTR design. Results of extensive criticality and depletion calculations with varying fuel loadings showed that VHTRs are capable for autonomous operation and HLW waste reduction when loaded with TRU fuel.

Copyright ( $) 2009$ T. G. Lewis III and P. V. Tsvetkov. This is an open access article distributed under the Creative Commons Attribution License, which permits unrestricted use, distribution, and reproduction in any medium, provided the original work is properly cited.

\section{Introduction}

The current waste management strategy for spent nuclear fuel (SNF) mandated by the US Congress is the disposal of high-level waste (HLW) in a geological repository at Yucca Mountain [1]. Ongoing efforts on closed-fuel cycle options and difficulties in opening and safeguarding such a repository have led to investigations of alternative waste management strategies [2]. One potential strategy for the US fuel cycle would be to make use of fuel loadings containing high concentrations of transuranic (TRU) nuclides in the next generation reactors $[1,3]$. The use of such fuels would not only increase fuel supply but could also potentially facilitate prolonged operation modes (via fertile additives) on a single fuel loading $[4,5]$.

To meet the demand for clean and reliable energy sources, the GEN-IV International Forum (GIF) was founded in early 2000 to investigate and develop technologies that could be incorporated into the next generation of power reactors [6, 7]. Through this international partnership around 100 different systems were evaluated to meet goals set forth by the forum. Of the nearly 100 systems studied by GIF, six were chosen in late 2002 to best meet goals set by the forum. Of these six concept systems, the VHTR is the most likely GEN IV system to be available in the near term.

The VHTR technology is based on the concepts originally developed for the US Fort St. Vrain and Peach Bottom reactors, as well as on the extensive international experience involving such facilities as the German AVR and THTR, Swiss PROTEUS, Chinese HTR-10, Japanese HTTR, and Russian GROG and ASTRA. The VHTR concept should be designed as a high-efficiency system capable of supplying electricity and process heat to a broad spectrum of high-temperature and energy-intensive processes. The reference reactor is a $600 \mathrm{MWth}$, helium-cooled core connected to an intermediate heat exchanger to deliver process heat, although direct cycles without the need of a heat exchanger have been proposed [7]. 
TABLE 1: Parameters of the Reference VHTR Design.

\begin{tabular}{|c|c|c|c|}
\hline Parameter & Value & Parameter & Value \\
\hline Fuel & $\mathrm{UO}_{2}$ & Power $\left(\mathrm{MW}_{\text {th }}\right)$ & 600 \\
\hline Enrichment $(\%)$ & 15 & Power Density $\left(\mathrm{W} / \mathrm{cm}^{3}\right)$ & 6.9 \\
\hline \multirow{2}{*}{ Coolant } & \multirow{2}{*}{$\mathrm{He}$} & Pressure $(\mathrm{MPa})$ & 7.0 \\
\hline & & Inlet/Outlet Temperature $\left({ }^{\circ} \mathrm{C}\right)$ & $490 / 950$ \\
\hline \multirow{3}{*}{ \# of Columns } & \multirow{3}{*}{102} & \# of fuel columns & 66 \\
\hline & & \# of control columns & 36 \\
\hline & & \# of blocks/column & 13 \\
\hline Block Pitch $(\mathrm{cm})$ & 36 & \# of fuel pins/fuel block & 32 \\
\hline \multirow{7}{*}{ Block Height $(\mathrm{cm})$} & \multirow{7}{*}{58} & \# of $\mathrm{B}_{4} \mathrm{C}$ rods/fuel block & 2 \\
\hline & & Control rods/control block & 2 \\
\hline & & Emergency rods/control block & 1 \\
\hline & & Compact pitch $(\mathrm{cm})$ & 5.15 \\
\hline & & Fuel hole radius $(\mathrm{cm})$ & 4.1 \\
\hline & & Compact inner radius $(\mathrm{cm})$ & 0.5 \\
\hline & & Compact outer radius $(\mathrm{cm})$ & 1.3 \\
\hline \multirow{7}{*}{ Packing (\%) } & \multirow{7}{*}{30} & $10.41 \mathrm{~g} / \mathrm{cm}^{3}$ kernel radius $(\mathrm{cm})$ & 0.02985 \\
\hline & & $1.14 \mathrm{~g} / \mathrm{cm}^{3}$ buffer radius $(\mathrm{cm})$ & 0.03588 \\
\hline & & $1.89 \mathrm{~g} / \mathrm{cm}^{3} \mathrm{PyC} 1$ radius $(\mathrm{cm})$ & 0.03895 \\
\hline & & $3.20 \mathrm{~g} / \mathrm{cm}^{3} \mathrm{SiC}$ radius $(\mathrm{cm})$ & 0.04184 \\
\hline & & $1.87 \mathrm{~g} / \mathrm{cm}^{3}$ PyC2 radius $(\mathrm{cm})$ & 0.04645 \\
\hline & & Matrix $\left(\mathrm{g} / \mathrm{cm}^{3}\right)$ & 1.77 \\
\hline & & Block $\left(\mathrm{g} / \mathrm{cm}^{3}\right)$ & 1.69 \\
\hline
\end{tabular}

The remarkable capability of TRISO-coated fuel particles to withstand radiation damage without failing allows for their use as a high burnup fuel form, as demonstrated in the "Deep Burn Concept" proposed by General Atomics (GAs) [5]. To account for radiation damage effects, fuel performance limits are expressed in terms of fast neutron fluence. For TRISO particles, the fast neutron fluence limits, depending on TRISO configuration, are around $5 \times 10^{25} \mathrm{n} / \mathrm{m}^{2}$ [8]. Utilization of TRUs/MAs in VHTRs facilitates development of advanced fuel cycles and supports fuel supply sustainability. Under certain spectral conditions, TRUs/MAs would be able to contribute to a core neutron balance compensating for depletion. The resulting self-stabilization of advanced actinide fuels is expected to prolong operation on a single fuel loading up to lifetimes limited by structural/integrity characteristics [4]. With spectrum shifting, there is a possibility to use VHTRs in waste management. The spectrum shifting takes advantage of the more favorable fission cross-sections for nuclides in TRUs at higher energies.

A TRUs/MAs-bearing fuel is the major challenge in the development of the partitioning and transmutation engineering technologies. To support analysis of the VHTR configurations with advanced actinide fuels, the present studies were focused on actinide compounds that are currently being considered and/or are under development for use as TRUs/MAs-bearing transmutation fuels [5]. This information is used to facilitate realistic studies of the VHTRs with MAs. The utilization of TRU/MAs, from lightwater reactor (LWR) fuel, for the prolonged-life VHTRs would reduce the need for the creation of more geological repository volume per decade of reactor operation [9].

\section{Reference VHTR Configuration}

In the present analysis, the TRU-fueled VHTR blocks have been designed using the HTTR geometry data [10]. Table 1 summarizes parameters of the reference VHTR design. To assure comprehensive and realistic assessment, extensive benchmark evaluations were performed based on the HTTR experimental program results $[4,10]$. Obtained benchmark results are in agreement with the available HTTR data and confirm applicability of the chosen modeling approach as it described in what follows [4].

The overall layout of the basis reference case is developed according to the VHTR/NGNP specifications. The reactor is assumed to be operated at $600 \mathrm{MWth}$. [11] The major difference with the VHTR/NGNP point design is that the reference case uses HTTR block specifications.

\section{Prototypic PWR Spent Fuel Composition}

To assure realistic quantification of the advanced actinide fuels, the characteristics of the materials, which DOE has considered for disposal in the proposed Yucca Mountain repository, are used to derive the reference nuclide distributions in the present analysis. The published final environmental impact statement data are the basis for the 
TABLE 2: PWR TRU vector (41,200 MWd/MTHM, 3.75\% BOL enrichment, 23 years decay).

\begin{tabular}{cccc}
\hline Element & Nuclide & $\begin{array}{c}\text { Decay Heat } \\
(\mathrm{W} / \mathrm{g})\end{array}$ & $\begin{array}{c}\text { TRU Composition } \\
\text { (atom \%) }\end{array}$ \\
\hline $\mathrm{Np}$ & ${ }^{237} \mathrm{~Np}$ & 0.00002 & 6.121 \\
\hline \multirow{4}{*}{$\mathrm{Pu}$} & ${ }^{238} \mathrm{Pu}$ & 0.56000 & 1.986 \\
& ${ }^{239} \mathrm{Pu}$ & 0.00200 & 51.718 \\
& ${ }^{240} \mathrm{Pu}$ & 0.00700 & 21.899 \\
& ${ }^{241} \mathrm{Pu}$ & 0.00400 & 4.104 \\
& ${ }^{242} \mathrm{Pu}$ & 0.00010 & 4.451 \\
\hline \multirow{3}{*}{$\mathrm{Am}$} & ${ }^{241} \mathrm{Am}$ & 0.11000 & 8.250 \\
& ${ }^{242 m} \mathrm{Am}$ & - & 0.020 \\
& ${ }^{243} \mathrm{Am}$ & 0.00700 & 1.230 \\
\hline \multirow{3}{*}{$\mathrm{Cm}$} & ${ }^{243} \mathrm{Cm}$ & 1.70000 & 0.003 \\
& ${ }^{244} \mathrm{Cm}$ & 2.80000 & 0.194 \\
& ${ }^{245} \mathrm{Cm}$ & - & 0.021 \\
& ${ }^{246} \mathrm{Cm}$ & - & 0.003 \\
& & & 100.00 \\
\hline
\end{tabular}

derived TRU composition used in the present analysis [9]. Table 2 provides the TRU composition that can be obtained for typical PWRs assuming burnup levels of 41.200 MWd/MTHM followed by cooling for 23 years.

\section{Methodology}

The analysis is performed using the ORNL SCALE 5.1 code system, and MatLab tool boxes. The code systems and tools for evaluations of uncertainty effects (nuclear and design/performance uncertainties) were developed on the basis of MatLab tool boxes and environments to support uncertainty analysis methodologies. The chosen approach links the applied neutronics code system and the generalized codes for universal sensitivity analysis, calibration, and uncertainty evaluations in a framework.

The applied overall computational approach takes advantage of the whole-core exact geometry Monte Carlodeterministic analysis methodology that has been implemented for coupled design studies of VHTRs with TRUs. Figure 1 shows the major modules and the code system framework formed and implemented for studies presented in this research. The neutronics analysis using a 3D whole-core VHTR model was performed using the ORNL SCALE code system [12]. The standard SCALE 5.1 TRITON sequence has been upgraded to allow fuel cycle modeling accounting for double heterogeneity effects. A combination of Matlab, Excel, and Perl was used to build SCALE input files and analyze SCALE output data as shown in Figure 1.

CSAS25 is one of several control sequences within CSAS that uses KENO V.a to evaluate criticality of 3D systems. CSAS25 is used exclusively in this research for the determination of VHTR performance characteristics at the beginning of life (BOL). CSAS25 allows for near-explicit accounting for lattice effects due to double heterogeneity

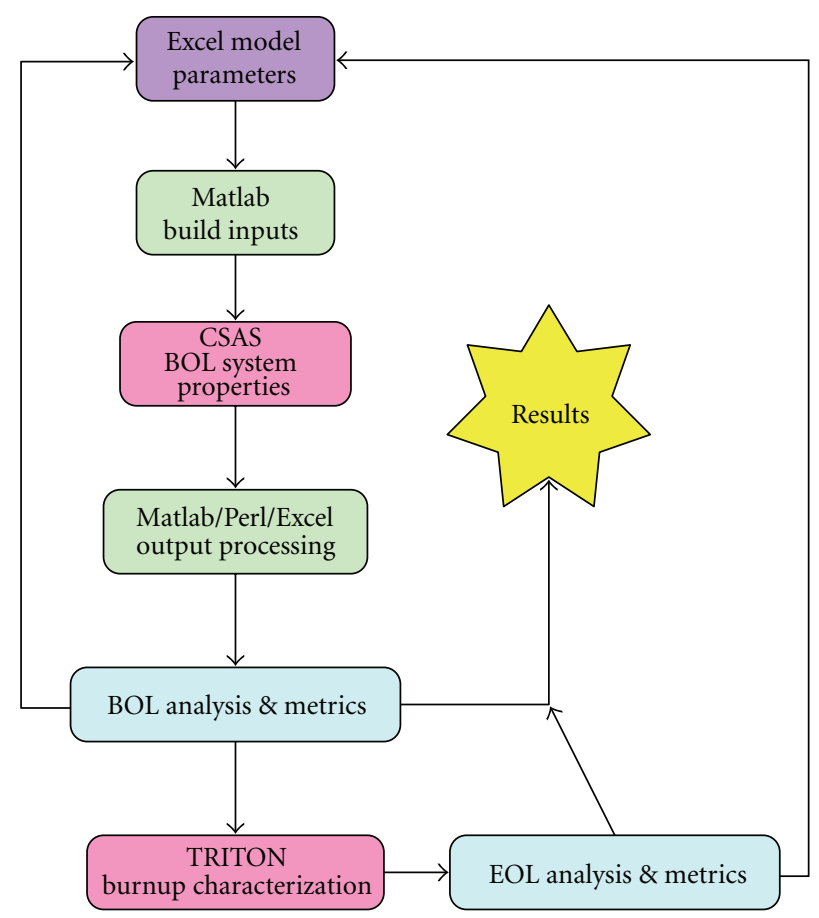

Figure 1: Applied computer code system.

features that are characteristic for all HTGRs including VHTRs.

Double heterogeneity can be thought of as a doublelevel geometry. In VHTRs, the first geometry level is formed by randomly-distributed TRISO-coated particles within a graphite matrix of the fuel compact. The second level is formed by a regular hexagonal lattice of fuel compacts within fuel blocks. A special treatment must be used for such systems because of substantial differences in neutron distributions at each heterogeneity level. Each compact has a fuel region containing thousands of microparticles that form a universe, which clearly exhibits features of an infinite lattice by itself. Only peripheral particles feel the presence of neighboring compacts. As a result, the core neutron distribution is formed by neutron media within each compact and then at the block and the whole core level.

To illustrate physics features of VHTRs and how they are accounted for in the applied multi-heterogeneity modeling approach, the fluxes calculated with SCALE 5.1/CSAS25 at various multiheterogeneity treatment levels are shown in Figure 2:

Infinite TRISO lattice (CENTRM calculations) - the calculations are performed at the infinite TRISO lattice level accounting explicitly for TRISO micro-particles and graphite matrix. The observed hard spectrum is the result of a closed packed lattice with the limited amount of moderating materials (TRISO coatings and matrix graphite only). These calculations are performed to prepare shielded cross-sections for compact lattice calculations.

Infinite compact lattice (CENTRM calculations) - the calculations are performed at the infinite compact lattice level with properly homogenized fuel regions in compacts 


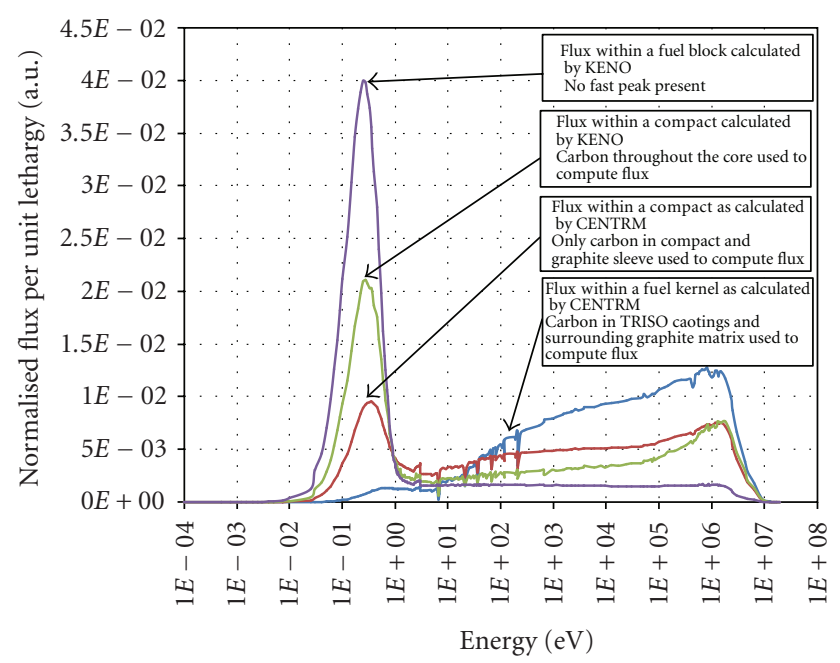

FIgure 2: Fluxes in VHTRs at different levels of the double heterogeneity treatment.

using cross-sections from the earlier step. At this level, the model includes both the homogenized mix of TRISO microparticles and compact matrix graphite and the graphite block graphite. Fuel compact external dimensions and their arrangement are preserved. Because of the significantly larger amount of moderating materials, the compact lattice flux exhibits the well-defined thermal peak. These calculations are performed to prepare cross-sections for use in whole-core Monte Carlo calculations with KENO V.a.

Finite compact lattice (KENO V.a calculations)-the calculations are performed at the whole-core exact geometry level using the homogenized cross-sections for compact fuel regions. The difference between infinite and finite lattice calculations are clearly visible and are due to the increased amount of moderating materials as well as fast neutron streaming through various passages in the VHTR core hexagonal block assembly.

Figure 2 is also showing the overall VHTR block-averaged neutron distribution that was produced with multi-group cross-sections prepared following the lattice/configuration structures as described earlier.

The SCALE/TRITON was developed to handle 2D and 3D depletion scenarios such as axial enrichment of boiling water reactors (BWRs) and the effects associated with strong absorbers. There are 5 TRITON sequences, each one having unique abilities while sharing common subroutines. In this research, the TRITON T5-DEPL sequence was used with a modification to allow for depletion of double heterogeneous materials. This sequence uses the KENO V.a functional module at the $3 \mathrm{D}$ whole-core modeling level.

The model was developed taking advantage of the robust capabilities of SCALE 5.1, including the complexity of adding a temperature distribution to the model. This temperature distribution was implemented in the VHTR model through additional materials and regions. This is exemplified in the most complex model, where a total of 511 different materials were used to encompass major features of a VHTR. These

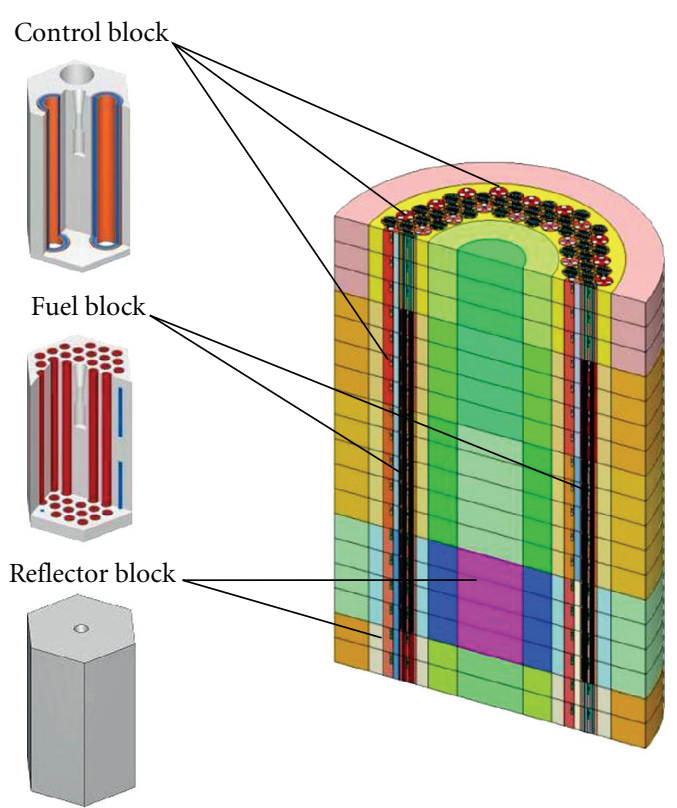

FIGURE 3: 3D whole-core model of the reference VHTR configuration.

features range from graphite blocks to the individual coatings of TRISO particles. The sequential creation of SCALE inputs and their corresponding output required an automated process. This process was managed via the Matlab script that was capable of producing and managing the creation of inputs and postprocessing evaluations of the corresponding outputs. Figure 3 shows the applied 3D whole-core VHTR model [11].

The geometry of the VHTR was created for use with SCALE 5.1 sequences focusing on KENO V.a. at the wholecore modeling level. As described earlier, the model created is a near exact depiction of the expected physical description of a power-size VHTR. The fundamental building blocks of the reactor (e.g., fuel blocks and its constituents) and the ratio of these blocks (control rod guide blocks to fuel block ratio) to one another are based on HTTR design parameters, while the overall configuration of the reactor has been developed following the DOE VHTR design requirements. The modeling adequacy is confirmed by performing series of experiment-to-code benchmark evaluations [4].

\section{Parametric Analysis at the Beginning of Life Conditions}

The series of BOL VHTR configurations were analyzed using the CSAS25 sequence of the SCALE 5.1 code system. Analysis of BOL cores is important to determine systems with acceptable safety characteristics, as well as a desirable BOL reactivity margins. Further analysis was done to determine system's performance characteristics during operation.

Figure 4 shows the 3D BOL neutron distribution in the reference LEU-fueled VHTR configuration. The specification of this design is given in Table 1. The neutron leakage effects at the core top and bottom resulted in decreasing thermal 


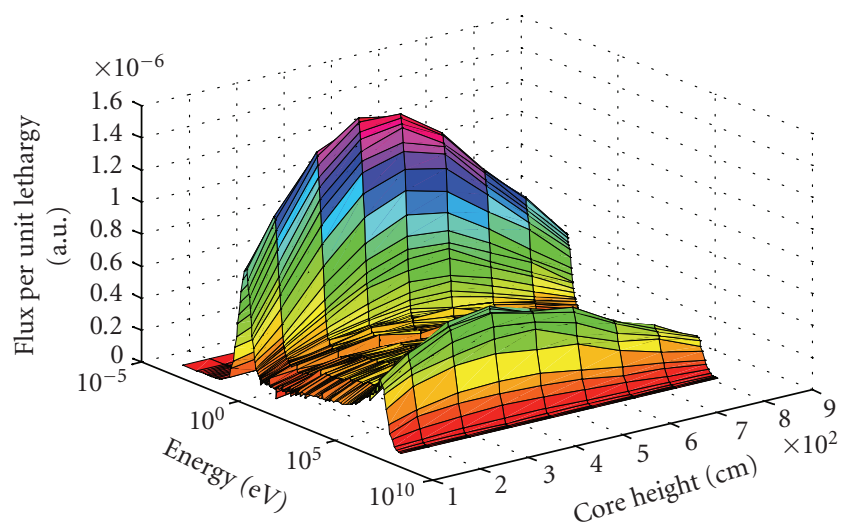

FIGURE 4: 3D space-energy neutron distribution in the reference LEU-fueled VHTR (neutron fluxes in compacts of the innermost fuel ring as a function of their axial locations in the VHTR core).

TABLE 3: Reactor physics parameters for three and four ring LEUVHTR configurations.

\begin{tabular}{cccc}
\hline $\begin{array}{c}\text { Number of } \\
\text { rings }\end{array}$ & Enrichment & $\begin{array}{c}\text { Effective } \\
\text { multiplication } \\
\text { factor }\end{array}$ & $\begin{array}{c}\text { Average neutron } \\
\text { lethargy causing } \\
\text { fission }(\mathrm{eV})\end{array}$ \\
\hline 3 & 3 & 0.863 & $\mathrm{n} / \mathrm{a}$ \\
3 & 8 & 1.181 & 0.2188 \\
3 & 9 & 1.214 & 0.2316 \\
3 & 10 & 1.239 & 0.2463 \\
3 & 15 & 1.328 & 0.3168 \\
3 & 20 & 1.409 & 0.3994 \\
3 & 40 & 1.481 & 0.8380 \\
\hline 4 & 3 & 0.903 & $\mathrm{n} / \mathrm{a}$ \\
4 & 8 & 1.218 & 0.2229 \\
4 & 9 & 1.252 & 0.2106 \\
4 & 10 & 1.278 & 0.2524 \\
4 & 15 & 1.365 & 0.3295 \\
4 & 20 & 1.414 & 0.4158 \\
4 & 40 & 1.510 & 0.8926 \\
\hline
\end{tabular}

and fast flux peak magnitudes. The distribution is typical for LEU VHTRs and will be used as the reference basis for evaluations of TRU-fueled VHTRs.

In the present analysis, recognizing configuration flexibility of VHTRs, the annular cores with three and four fuel block rings are taken into consideration. The effect of enrichment on the basic reactor physics characteristics of VHTRs is illustrated in Table 3 . Table 3 illustrates "number of rings" effects in LEU-fueled systems by providing the multiplication factors and the corresponding neutron lethargies causing fissions as a function of enrichment. The lethargies are given to illustrate anticipated spectral changes due to enrichment and core configuration variations.

Table 4 illustrates the corresponding effects of design modifications in the TRU-fueled systems. The analysis was performed assuming 100\% TRU-filled kernels. Because the fissile content of TRUs is determined by the composition, the

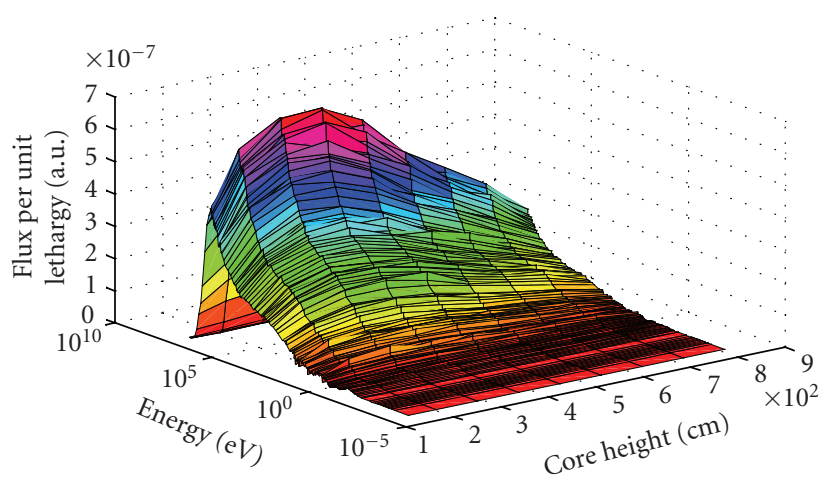

FIGURE 5: 3D space-energy neutron distribution in the TRU-fueled VHTR (neutron fluxes in compacts of the innermost fuel ring as a function of their axial locations in the TRU-fueled core $(55.86 \%$ fissile atom fraction, $\mathrm{C} / \mathrm{HM}=25)$ ).

carbon-to-heavy metal (C/HM) atom ratio is varied inside a fuel compact for VHTRs with TRUs. In the VHTR systems, these variations can be accomplished by changing numbers of TRISO particles per compact. As for the LEU-cases, lethargies are provided to characterize spectral fluctuations in response to the considered design modifications. The packing fractions and the corresponding $\mathrm{C} / \mathrm{HM}$ ratios are provided. It has to be noted that this analysis is performed for the TRU-fueled VHTR configurations with packing fractions under $8 \%$. These packing fractions are consistent with currently feasible TRU loadings per compact and the refueling intervals of approximately 2 years $[5,8]$.

As shown later (see Table 6), the packing fractions under $8 \%$ lead to relatively short refueling intervals. Only the TRUfueled systems with packing fractions over $8 \%$ are capable for prolonged operation on a single fuel loading assuming the same power density as in the reference configuration. These high-TRU-content systems are very different from the conventional LEU-fueled VHTRs because the effect of $\mathrm{C} / \mathrm{HM}$ on the flux in the TRU-fueled VHTRs is far more complex when compared to the effects on LEU systems. For comparison, the flux shown in Figure 5 is for a TRU-fueled VHTR with a C/HM atom ratio of 25 . The flux shape in this reactor has no thermal peak present in the compact. This suggests that low C/HM TRU-fueled systems are capable of utilizing fast neutrons much better than higher ratio systems. The ability of these systems to manage utilization of neutrons is beneficial for optimization efforts to attain prolonged refueling intervals.

Reactivity coefficients were calculated to evaluate safety characteristics of TRU-fueled VHTRs. Four isothermal VHTR configurations were modeled with CSAS25. The results are shown in Table 5. In these studies, the $\mathrm{C} / \mathrm{HM}$ atom ratios are varies from 70 to 25 for the TRU-fueled systems and from 80 to 30 for the LEU-fueled systems. The variations are chosen to achieve the same neutron multiplication levels in TRU- and LEU-fueled systems.

In TRU systems, the low $\mathrm{C} / \mathrm{HM}$ atom ratio leads to the temperature reactivity coefficient that is approximately two times larger in its absolute value than the temperature 
TABLE 4: Reactor physics parameters for three and four ring TRU-VHTR configurations.

\begin{tabular}{|c|c|c|c|c|}
\hline Number of rings & Packing fraction (\%) & $\mathrm{C} / \mathrm{HM}$ & $\begin{array}{c}\text { Effective } \\
\text { multiplication factor }\end{array}$ & $\begin{array}{c}\text { Average neutron } \\
\text { lethargy causing } \\
\text { fission }(\mathrm{eV})\end{array}$ \\
\hline 3 & 2.0 & 733 & 1.0759 & 0.25 \\
\hline 3 & 3.0 & 520 & 1.0840 & 0.27 \\
\hline 3 & 4.0 & 414 & 1.0808 & 0.29 \\
\hline 3 & 6.0 & 308 & 1.0645 & 0.39 \\
\hline 3 & 8.0 & 255 & 1.0521 & 0.53 \\
\hline 4 & 2.0 & 632.44 & 1.1134 & 0.25 \\
\hline 4 & 3.0 & 504.66 & 1.1155 & 0.27 \\
\hline 4 & 4.0 & 419.47 & 1.1105 & 0.30 \\
\hline 4 & 6.0 & 249.10 & 1.0945 & 0.41 \\
\hline 4 & 8.0 & 176.08 & 1.0818 & 0.55 \\
\hline
\end{tabular}

TABLE 5: BOL isothermal temperature reactivity coefficients of VHTRs with LEU and TRU.

\begin{tabular}{lc}
\hline Case summary & $\begin{array}{c}\text { Temperature reactivity } \\
\text { coefficient }(\Delta k / k / K)\end{array}$ \\
\hline LEU, C/HM $=80$, Enrichment $=15 \%$ & $-1.95 \mathrm{E}-05$ \\
$\mathrm{LEU}, \mathrm{C} / \mathrm{HM}=30$, Enrichment $=15 \%$ & $-3.43 \mathrm{E}-05$ \\
$\mathrm{TRU}, \mathrm{C} / \mathrm{HM}=70$ & $-5.07 \mathrm{E}-05$ \\
TRU, C/HM $=25$ & $-7.16 \mathrm{E}-05$ \\
\hline
\end{tabular}

TABLE 6: Lifetime of VHTRs with TRUs*.

\begin{tabular}{cc}
\hline C/HM atom ratio & Core life [years] \\
\hline 9 & 9 \\
11 & 8 \\
23 & 7 \\
33 & 6 \\
53 & 6 \\
112 & 5 \\
229 & 2 \\
\hline
\end{tabular}

* Packing fraction of $30 \%$ corresponds to the C/HM ratio of 138 (12467 particles per compact).

reactivity coefficient in the corresponding low C/HM LEUsystem.

\section{Single-Batch Operation of the TRU-Fueled VHTRs}

Several TRU-fueled VHTR configurations have been analyzed to determine the effect of the $\mathrm{C} / \mathrm{HM}$ atom ratio on the single-batch core lifetime. All of the considered TRUfueled VHTR configurations were developed on the basis of the developed reference VHTR design (see Table 1). As illustrated in Table 6, the longest core lifetimes are shown to be approximately nine years for TRU-VHTRs.

The refueling interval was constrained by excess reactivity requirements although fast fluence levels were evaluated. It was assumed that the effective multiplication factor should not drop below 1.01 during operation. This value was chosen as the EOL criterion.

The computed fast fluences are within published performance limits for all considered LEU- and TRU-fueled VHTRs [8]. For example, the TRU-fueled VHTR system is capable of operation for approximately 4 years assuming the volume fraction of $30 \%(\mathrm{C} / \mathrm{HM}=138)$. The corresponding fast fluence is $2.14 \times 10^{22} \mathrm{n} / \mathrm{cm}^{2}$. The extended batch mode operation without refueling can be prolonged further by decreasing power densities in the TRU-fueled VHTR cores.

\section{Conclusions}

The effects of $\mathrm{C} / \mathrm{HM}$ atom ratio variations on $\mathrm{BOL}$ excess reactivity levels and neutron distributions in the VHTR configurations have been analyzed by varying the packing fraction of TRISO particles inside the compact. Larger values of the $\mathrm{C} / \mathrm{HM}$ atom ratios result in smaller $\mathrm{BOL}$ excess reactivity levels for the VHTR configurations with the same refueling interval. Consequently, these design adjustments can be used as a tool to minimize reactivity swings in the feasible VHTR design. The C/HM atom ratio adjustments allow controlling neutron distributions in the VHTR cores and potentially may lead to prolonged refueling intervals. Although indicating some technical limitations and challenges, studies of VHTRs with TRUs/MAs definitely suggest promising performance and possibility to utilize the core configurations with TRUs/MAs gaining prolonged operation and self-sustainability.

Fluence-related limitations (radiation damage) are the most significant constraints on achievable operation times. This constraint can be relaxed or even eliminated by reducing power density levels and using advanced radiationtolerant materials for extended-life VHTR configurations. However, the use of advanced materials will adversely impact economics characteristics. It is instructive to note that acceptable safety characteristics have been observed for all configurations.

The extended-lifetime approach could reduce the technical need for additional repositories and should also improve 
marketability of the Generation IV VHTR designs as smallto-medium internationally deployable energy sources for electricity generation and industrial heat applications. The TRU-fueled VHTRs offer performance characteristics that would be difficult to achieve in analogous LEU-fueled systems: almost a decade-long batch mode operation without intermediate refueling; significant reductions of initial excess reactivity levels (smaller lifetime reactivity swings); and inherently higher achievable burnup levels.

\section{Disclaimer}

This paper was prepared as an account of work sponsored by an agency of the United States Government. Neither the United States Government nor any agency thereof, nor any of their employees, makes any warranty, express, or implied, or assumes any legal liability or responsibility for the accuracy, completeness, or usefulness of any information, apparatus, product, or process disclosed, or represents that its use would not infringe privately owned rights. Reference herein to any specific commercial product, process, or service by trade name, trademark, manufacturer, or otherwise does not necessarily constitute or imply its endorsement, recommendation, or favoring by the United States Government or any agency thereof. The views and opinions of authors expressed herein do not necessarily state or reflect those of the United States Government or any agency thereof.

\section{Nomenclature}

AFCI: Advanced fuel cycle initiative

BOL: Beginning-of-life

C/HM: Carbon-to-heavy metal atom ratio

DB: Deep-burn concept

EOL: End-of-life

HLW: High level waste

HM: Heavy metal

HTGR: High temperature gas-cooled reactor

LANL: Los Alamos National Laboratory

LEU: Low-enriched uranium

LLW: Low level waste

LWR: Light water reactor

MA: Minor actinides ( $\mathrm{Np}, \mathrm{Am}, \mathrm{Cm}$ )

NERI: Nuclear energy research initiative

ORNL: Oak Ridge National Laboratory

P\&T: Partitioning and transmutation

SNF: Spent nuclear fuel

TRU: Transuranic nuclides

VHTR: Very high temperature reactor

a.u.: Arbitrary units

\section{Acknowledgment}

This paper is based upon work supported by the US Department of Energy under Award Number DE-FC0705ID14655 (05-094).

\section{References}

[1] E. ElBaradei, "Nuclear power and sustainable development," IAEA, 2006.

[2] "Report to Congress on advanced fuel cycle initiative: the future path for advanced spent fuel treatment and transmutation research," Tech. Rep. 03-GA50439-06, U.S. DOE, 2003.

[3] "Report to Congress on Spent Nuclear Fuel Recycling Program Plan," U.S. DOE, 2006.

[4] P. V. Tsvetkov, D. E. Ames II, A. B. Alajo, and T. G. Lewis III, "Spectrum shifting as a mechanism to improve performance of VHTRs with advanced actinide fuels," Nuclear Engineering and Design, vol. 238, no. 8, pp. 1958-1964, 2008.

[5] T. Kim, T. Taiwo, R. Hill, W. Yang, and F. Venneri, "A feasibility study of reactor-based deep-burn concepts," Tech. Rep. ANLAFCI-155, Argonne National Laboratory, 2005.

[6] Office of Nuclear Energy, Science, and Technology, "The US generation IV implementation strategy," 03-GA50439-06, United States of America, 2003.

[7] "Generation IV Nuclear Energy Systems Ten Year Program Plan Volume I," Office of Nuclear Energy, Science, and Technology, U.S. DOE, March 2005.

[8] D. Hanson, "Screening Tests for Selection of VHTR Advanced Fuel," General Atomics, San Diego, Calif, USA, 2003.

[9] "Final Environmental Impact Statement for a Geologic Repository for the Disposal of Spent Nuclear Fuel and HighLevel Radioactive Waste at Yucca Mountain, Nye County, Nevada," Vol. 2, Appendix A, "Inventory and Characteristics of Spent Nuclear Fuel, High-Level Radioactive Waste, and Other Materials", DOE/EIS-0250, U.S. DOE, 2002.

[10] "Evaluation of high temperature gas-cooled reactor performance: benchmark analysis related to initial testing of the HTTR and HTR-10," Tech. Rep. IAEA-TECDOC-1382, International Atomic Energy Agency, Vienna, Austria, 2003.

[11] P. M. Mills, R. Soto, and G. Gibbs, "Next generation nuclear plant pre-conceptual design report," INL Report INL/EXT-0712967 Rev. 1, NGNP Project, 2007.

[12] "SCALE: a modular code system for performing standardized computer analyses for licensing evaluation," Tech. Rep. ORNL/TM-2005/39, Ver. 5.1, Oak Ridge National Laboratory, Oak Ridge, Tenn, USA, November 2006. 

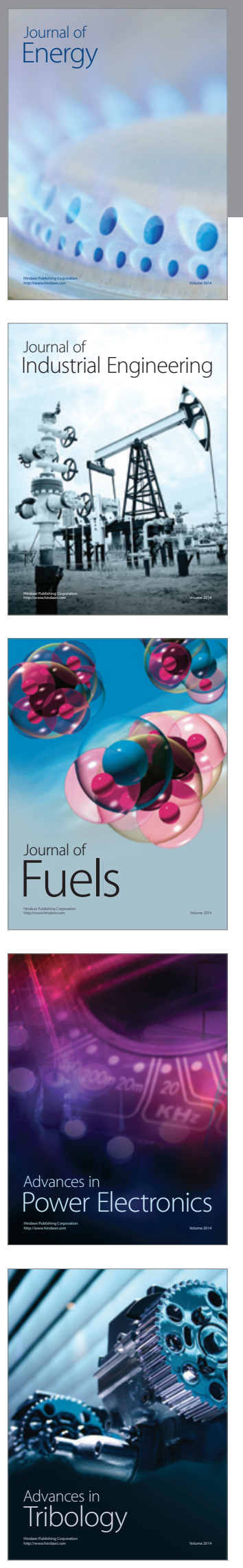
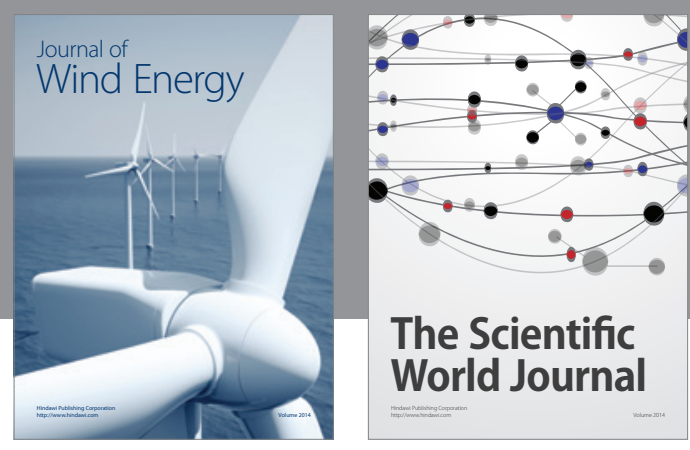

The Scientific World Journal

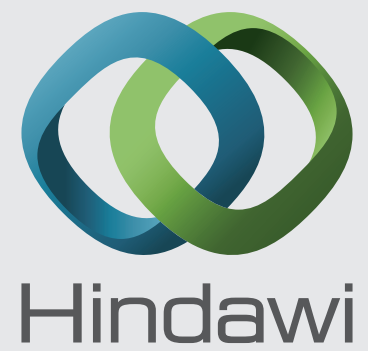

Submit your manuscripts at http://www.hindawi.com
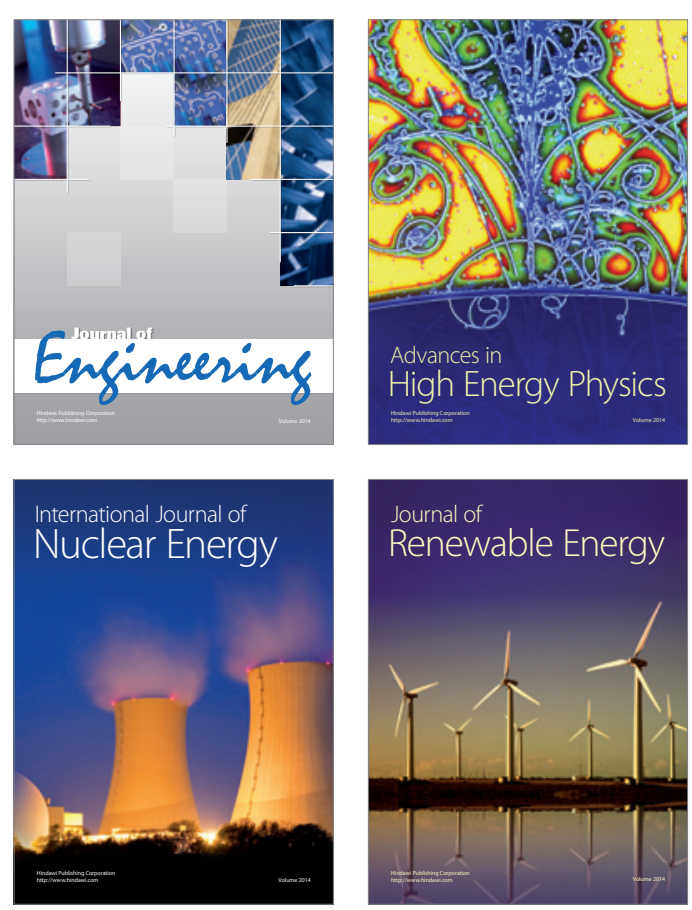

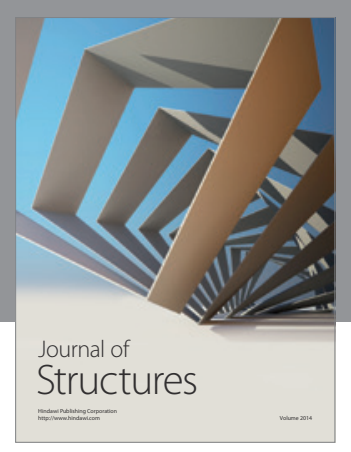

Rotating
Mechinery
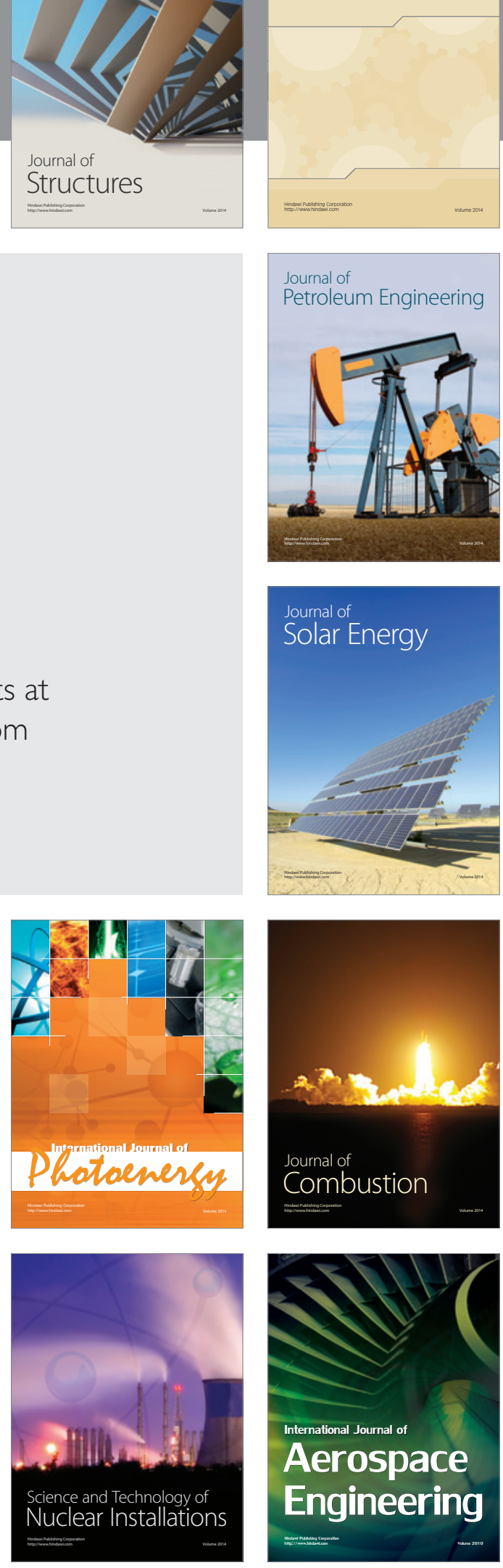